\title{
Mapeamento de alunos público-alvo da educação especial na Universidade Federal de São Carlos em 2014-2015
}

\author{
Gerusa Ferreira Lourenço \\ Universidade Federal de São Carlos - São Carlos - SP - Brasil \\ Janna Battistella \\ Universidade Federal de São Carlos - São Carlos - SP - Brasil
}

\begin{abstract}
Resumo
Objetivou-se realizar o mapeamento dos estudantes público-alvo da Educação Especial nos cursos de graduação da Universidade Federal de São Carlos no período de 2014 e 2015. As estratégias para coleta dos dados foram: acesso aos dados institucionais sobre a caracterização autodeclarada dos estudantes, envio de email aos estudantes identificados para confirmação das demandas apresentadas, convite e aplicação de um questionário aos estudantes, contato com Pró-reitorias e coordenações de curso de graduação. Os dados foram registrados em planilhas e sistematizados via análises descritivas e de conteúdo. Obteve-se média de 124 estudantes registrados no sistema, com a confirmação de 27 que atendiam as classificações colocadas para esse alunado. Discutem-se as fragilidades e implicações da coleta de dados institucional sobre esse público contar primariamente com a autodeclaração.
\end{abstract}

Palavras-chave: Educação especial; inclusão escolar; ensino superior.

\section{Mapping of special education target students at the Federal University of São Carlos in 2014-2015}

\begin{abstract}
The objective of this study was to map the students of special education in the undergraduate courses of the Federal University of São Carlos in the period of 2014 and 2015. The strategies for data collection were: access to institutional data on self-reported characterization of students, sending e-mails to identified students to confirm the applications presented, inviting and applying a questionnaire to students, contacting Rectories and coordinating undergraduate courses. The data were recorded in spreadsheets and systematized through descriptive and content analyzes. A mean of 124 students enrolled in the system was obtained, with a confirmation of 27 that met the classifications placed for this student. It discusses the weaknesses and implications of institutional data collection on this audience rely primarily on self-declaration.
\end{abstract}

Keywords: Special education; school inclusion; higher education.

\section{Mapeo de alumnos público-objetivo de la educación especial en la Universidad Federal de São Carlos en 2014-2015}

\section{Resumen}

En este estudio se tuvo por objetivo realizar el mapeo de los estudiantes público-objetivo de la Educación Especial en los cursos de graduación de la Universidad Federal de São Carlos en el período de 2014 y 2015. Las estrategias para la recolecta de los datos fueron: acceso a los datos institucionales sobre la caracterización auto-declarada de los estudiantes, envío de e-mail a los estudiantes identificados para confirmación de las demandas presentadas, invitación y aplicación de un cuestionario a los estudiantes, contacto con Pro-rectorías y coordinaciones de curso de graduación. Se registraron los datos en planillas y sistematizados vía análisis descriptivos y de contenido. Se obtuvo un promedio de 124 estudiantes registrados en el sistema, con la confirmación de 27 que atendían a las clasificaciones colocadas para ese alumnado. Se discute las fragilidades e implicaciones de la recolecta de datos institucional sobre ese público contar primariamente con la auto-declaración.

Palabras clave: Educación especial; inclusión escolar; enseñanza universitaria. 


\section{Introdução}

O conceito de inclusão escolar tem sido direcionado a compreender o acesso contínuo e com qualidade ao espaço educacional a todos os estudantes. Nos últimos anos, o esforço nessa direção propiciou o avanço em leis, decretos, resoluções e portarias que fossem capazes de abranger as especificidades no atendimento escolar de uma população com diversidades amplas de características e demandas para o processo de ensino-aprendizado denominados atualmente como o público-alvo da Educação Especial (Brasil, 2008; Unesco, 2009; Lei $\left.n^{\circ} 13.146,2015\right)$.

No entanto, Guerreiro (2011) relata em seus estudos que os direitos das minorias a atingirem o nível mais alto da escolarização, principalmente aquelas que possuem histórico de exclusão no sistema educacional, precisam ser discutidos no âmbito das políticas de inclusão escolar que muitas vezes têm o foco nos anos iniciais. A problemática dessa situação está situada no que diz respeito ao descompasso entre as legislações e das normas perante o que é evidenciado em pesquisas sobre a realidade das instituições de ensino superior no país (Cabral, 2017; Torres, Calheiros, \& Santos, 2016). Segundo Ciantelli, Leite e Martins (2015) considerando o importante papel da universidade na produção e democratização do conhecimento entende-se que é nesse espaço que a transmissão de conhecimento científico ocorre com vistas ao desenvolvimento humano.

Moreira (2012) indica que é possível refletir que a criação de políticas que facilitam as minorias, principalmente aquelas que são excluídas no acesso à educação superior devem vir acompanhadas com o intuito de que esses estudantes possam competir em igualdade em processos de seleção e admissão nesse nível de ensino. Propõe ainda que a diminuição das desigualdades que são historicamente conhecidas e a garantia de igualdade de oportunidades aos grupos marginalizados: mulheres, negros, indígenas e pessoas com deficiência, são algumas das atividades realizadas através de movimentos da sociedade civil, assim como a criação de políticas afirmativas de inclusão que englobem a escola e a universidade.

Medidas mais diretivas para a inclusão escolar no ensino superior começaram a ser implantadas juntamente com a Política Nacional de Educação Especial na Perspectiva da Educação Inclusiva em 2008 (Brasil, 2008). Essa proposta visa acompanhar os avanços nas lutas sociais e dos conhecimentos buscando constituir políticas públicas que promovam uma educação de qualidade para todos os estudantes em todos os níveis de escolarização. Dentre as iniciativas está o Programa de Acessibilidade na Educação Superior (Incluir) que propõe ações para o acesso às Instituições Federais de Ensino Superior (IFES). O principal objetivo é criar e consolidar núcleos de acessibilidade nas IFES, que respondem pela organização das ações institucionais, garantindo assim a integração dos estudantes público-alvo da educação especial na vida acadêmica.

Castro e Almeida (2014) evidenciam que políticas começaram a ser implementadas de maneira mais diretiva a esse alunado após a criação dos núcleos de acessibilidade em universidades como UFRJ, UERN, UFPR e UFPB a partir de 2008.

Nesse sentido, o acesso ao ensino superior de estudantes denominados público-alvo da Educação Especial vem de forma tímida alcançando patamares importantes; porém, requer a implementação de medidas que facilitem e concretizem ações para acesso e permanência na instituição (Santos \& Fumes, 2012).

Porém, autores como Maia, Rahme e Diniz (2014) apontam que estudantes com deficiência podem apresentar algumas limitações de natureza física, sensorial, cognitiva, sendo assim necessário pensar em adequações de práticas curriculares e até mesmo no que diz respeito às suas particularidades como pessoa. Para que o aluno se sinta integrado no âmbito da universidade, ele deve ter um contato que seja diferenciado daquele que obteve em sua outra formação, que garanta acesso a oportunidades e trocas com os demais estudantes. Almeida, Bellosi e Ferreira (2015) apontam que os principais problemas de garantia da permanência no âmbito universitário são justificados pelas especificidades das diversas deficiências, pela falta de recursos tecnológicos acessíveis, pelo número reduzido de profissionais especializados e pela falta de acessibilidade física na maioria dos campi universitários.

Zuliani, Oliveira, Kretzmann, e Castro (2014) ressaltam que apesar de todas as reivindicações feitas, ainda assim, a maioria das pessoas com deficiência enfrenta muitas dificuldades para ingressar no ensino superior e, quando ingressam, encontram inúmeras dificuldades em sua permanência, decorrentes principalmente da falta de políticas institucionais, do acompanhamento e do fornecimento de recursos que atendam satisfatoriamente às suas necessidades educativas.

Díez e Rodríguez (2015) apresentam que na Universidade de Sevilla, o número de barreiras enfrentadas pelos estudantes público-alvo da Educação Especial supera os auxílios fornecidos a eles. Os estudantes se queixam de que a universidade deve proporcionar maior informação às pessoas que trabalham na instituição para lidar com a diversidade, indicando a necessidade de formação a toda a comunidade universitária. Nessa direção, Serrano (2015) se refere à inclusão salientando que a visão cubana impõe desafios às instituições do ensino superior introduzindo transformações em suas dinâmicas que ocorrem a partir de três processos: o acesso, a permanência e o egresso. Isso se faz necessário à formação de recursos humanos, dos professores, à organização dos recursos materiais, humanos e técnicos e o trabalho didático metodológico no processo de ensino e de aprendizagem. As chamadas "categorias de deficiências" são definidas com maior abrangência, além dos programas mais inclusivos e as adequações curriculares que se realizam.

Compreende-se então que a permanência do estudante na universidade vai muito além de política de cotas e prerrogativas que garantam esse acesso ao estudante. As relações estabelecidas entre o estudante e a instituição, por meio de políticas e ações institucionais, são cruciais para que haja assim uma troca de experiências e permita que 
o aluno entre em contato com toda a estrutura e contextos acadêmicos que podem compor a universidade, ampliando sua participação (Castro \& Almeida, 2014). Fernandes e Almeida (2007) reforçam que é necessário que a universidade crie condições para que o estudante seja integrado ao ambiente universitário de modo a promover não apenas sucesso acadêmico, mas também seu desenvolvimento psicossocial pleno. Isto envolve mudanças e/ou adaptações em vários aspectos por parte da comunidade universitária, como adaptação de materiais, acessibilidade física, capacitação de docentes, servidores e demais estudantes quanto ao conhecimento sobre as deficiências.

Quanto aos docentes, Lima e Moreira (2014) afirmam que os professores universitários possuem certo distanciamento no que diz respeito ao conhecimento sobre os estudantes público-alvo da Educação Especial, o que pode impactar negativamente nos processos de implementação de estratégias diferenciadas de ensino. Diante desse fato, Gil (2008) afirma que a maioria dos professores brasileiros, que leciona em estabelecimentos de ensino superior, não passou por qualquer processo sistemático de formação pedagógica para receber os estudantes público-alvo da Educação Especial, o que traz implicações importantes nesse fazer docente.

Nesse sentido, a literatura evidencia que são demandas atuais para favorecer o acesso ao ensino superior: formação continuada de professores, produção e adequação de recursos pedagógicos, assessoria psicopedagógica, adaptação ao currículo, até mesmo o que diz respeito a reflexões acerca da temática e como trabalhar e formar todos os envolvidos nesse processo (discentes, docentes, gestão e demais atores da comunidade universitária).

Dentre as importantes ações institucionais com vistas ao acesso e ao fornecimento de condições para a permanência desse grupo de estudantes, reforça-se a necessidade de que se estabeleçam estratégias de identificação e mapeamento dos estudantes público-alvo da Educação Especial presentes. Com a manutenção de um banco atualizado sobre esse público amplia-se a viabilidade de se obter parâmetros para o dimensionamento e, consequentemente, para o planejamento mais adequado e efetivo das políticas institucionais, por exemplo, favorecendo a atuação dos núcleos de acessibilidade.

O estudo de Santana, Donida, Monteiro e Silva (2015) revela que no contexto da Universidade Federal de Santa Catarina ainda há dificuldades que envolvem o mapeamento dos estudantes matriculados. Questões que se referem ao acesso às informações dos programas direcionados a esse público de estudantes e, também, ao que diz respeito ao real entendimento do próprio aluno no que se refere às políticas educacionais atuais, assim como a necessidade do preenchimento fidedigno de seus dados cadastrais junto às instituições de ensino são deficitárias. Achados como estes estão presentes no estudo de Zampar (2013) sobre a Universidade Federal de São Carlos (UFSCar) tendo como base os estudantes autodeclarados público-alvo da Educação Especial entre os anos de 2008 e 2012, com a presença de 72 alunos identificados à época.
Cabral (2017), em uma revisão integrativa da literatura nacional sobre inclusão no ensino superior, traz em seus resultados que dificuldades em realizar e manter um mapeamento eficaz desse público tem sido descrito e que pode trazer impactos negativos importantes na promoção de políticas institucionais mais efetivas de acolhida e permanência. Com isso, faz-se necessário a imersão nessa temática da qual se refere este estudo.

Assim, com o intuito de contribuir para a produção de conhecimento na temática de acessibilidade no ensino superior, o presente estudo está imerso em uma investigação ampla do Observatório Nacional de Educação (OBEDUC), denominada ACESSIBILIDADE NO ENSINO SUPERIOR: da análise das políticas públicas educacionais ao desenvolvimento de mídias instrumentais sobre deficiência e inclusão (OBEDUC/CAPES/INEP Edital no. 49/2012), e objetivou realizar o mapeamento dos estudantes público-alvo da Educação Especial em cursos de graduação da Universidade Federal de São Carlos (UFSCar) no período de 2014 e 2015. Os objetivos específicos foram: identificar o número de alunos com deficiência, transtornos globais do desenvolvimento e altas habilidades/superdotação ingressantes na universidade para os níveis de graduação entre os anos de 2014 e 2015; caracterizar a população identificada quanto ao curso e as categorias auto informadas; e identificar a forma como a universidade sistematiza as informações sobre essa população.

\section{Método}

A metodologia da pesquisa diz respeito a um estudo de caráter descritivo, com dados quanti e qualitativos (Gil, 1999). A pesquisa foi realizada na Universidade Federal de São Carlos, nos campi de São Carlos, Sorocaba, Araras e Lagoa do Sino, junto às Pró-reitorias de Graduação e Assuntos Comunitários e Estudantis e aos setores responsáveis pela sistematização dos dados censitários da Universidade.

Com seu início em 1968 no Campus São Carlos, a Universidade Federal de São Carlos oferece 62 cursos e um total de 2.807 novas vagas na graduação presencial. São 39 opções de cursos em São Carlos (1.797 vagas), seis em Araras (240 vagas), 14 em Sorocaba (620) e três em Buri (150 vagas). Há 48 departamentos acadêmicos divididos em oito centros: Ciências Agrárias, Ciências Biológicas e da Saúde, Ciências em Gestão e Tecnologia, Ciências e Tecnologias para a Sustentabilidade, Ciências Exatas e de Tecnologia, Ciências Humanas e Biológicas, Educação e Ciências Humanas e Ciências da Natureza.

Para a coleta e análise dos dados foram utilizados os seguintes materiais:

- Entrevista: foi construído um roteiro de entrevista semiestruturado conforme os direcionamentos do projeto maior em realização utilizado para direcionar a etapa de coleta realizada junto à Pró-Reitoria de Graduação. Esse roteiro foi composto por 23 questões que versavam sobre como a universidade coletava e tratava as informações de 
caracterização de seus estudantes para a composição dos dados informados no Censo do Ensino Superior de 2014.

- Banco de Dados: foi construída uma planilha de banco de dados a partir do Software Microsoft Access $₫$ de modo a registrar as informações advindas da coleta sobre o mapeamento dos estudantes;

- Questionário ao aluno: foi construído um questionário aplicado tanto presencialmente como online com os estudantes identificados pelo sistema de registro na universidade, de modo que o aluno pudesse detalhar as demandas que possui para seu processo de permanência no curso e os recursos de acessibilidade necessários. Esse questionário, com um total de onze questões, passou por validação com duas docentes da universidade que trabalham diretamente com a temática da educação especial.

Participaram do estudo os servidores responsáveis pela coleta e manutenção dos bancos de dados sobre a caracterização dos estudantes matriculados na Universidade vinculados às Pró-Reitorias de Graduação (Prograd) e de Assuntos Comunitários e Estudantis (Proace), Secretaria de Informática (SIN) e a Secretaria Geral de Planejamento e Desenvolvimento Institucionais (SPDI); e oito estudantes após a primeira identificação na etapa 2 do estudo.

Os procedimentos do estudo foram baseados em seis etapas, a saber:

Etapa Preliminar de cuidados éticos: Ressalta-se que a presente proposta estava vinculada ao projeto maior do OBEDUC, o qual foi submetido e aprovado por Comitê de Ética em Pesquisa com Seres Humanos [ $n^{\circ}$ de parecer omitido para não identificação dos autores] e todos os participantes do estudo autorizaram sua realização.

1. Consulta à Pró-Reitoria de Graduação: o objetivo dessa etapa consistiu em coletar informações sobre os dados censitários da universidade quanto à matrícula anual dos estudantes entre o período de 2014 a 2015 de modo a investigar se havia registros específicos sobre a população de interesse. O procedimento realizado consistiu na aplicação do roteiro de entrevista construído sobre o processo de captação e tratamento das informações sobre a caracterização dos estudantes de graduação da UFSCar.

2. Acesso aos dados da SIN: após autorização junto à Prograd houve o contato com a SIN que é responsável pelo sistema de informática da universidade e, por tanto, da tutela dos dados sistematizados sobre a caracterização dos estudantes. A partir da solicitação realizada pelo estudo, a presente etapa consistiu no acesso ao banco de dados sobre os estudantes que informaram possuir uma necessidade especial em seu cadastro inicial de matrícula. Dessa forma, foi possível obter dados quanto ao curso de origem, ano de ingresso, categoria de necessidade especial informada pelo estudante e o seu email de contato. Cabe a ressalva que nesse estudo optou-se por manter as categorias do públicoalvo da Educação Especial utilizadas pela universidade, baseadas na classificação do Censo do Ensino Superior do ano de 2014, uma vez que era a forma institucional de coleta dos dados junto aos estudantes. São elas: cegueira, visão subnormal ou baixa visão, deficiência auditiva, deficiência física, altas habilidades/superdotação, deficiência intelectual, condutas típicas, outras necessidades, agregadas às categorias surdez, deficiência múltipla, autismo, síndrome de RETT, surdocegueira, síndrome de Asperger e transtorno desintegrativo da infância.

3. Contato com os estudantes: Com os estudantes mapeados, a etapa três consistiu no envio de e-mail a todos os estudantes que indicaram possuir alguma demanda dentre as categorias que compunham o público-alvo da Educação Especial. Assim, a proposta foi de criação de um e-mail para que houvesse uma primeira aproximação com os estudantes que se autodeclararam em seu cadastro de modo a confirmar o dado por ele informado e também para iniciar a coleta de informações mais específicas sobre seu processo de escolarização atual na UFSCar e possíveis demandas. Esse contato ocorreu entre os meses de fevereiro e junho de 2015, com o envio de até três e-mails a cada aluno para seu retorno. Vale ressaltar que esse contato ocorreu em parceria com o núcleo de acessibilidade da universidade e todos os cuidados éticos foram tomados para manter o sigilo das informações específicas sobre os estudantes contatados.

4. Preenchimento do questionário: a partir do retorno positivo aos e-mails, os estudantes que confirmaram ser público-alvo da Educação Especial foram convidados a preencher o questionário construído para esse fim. O estudante tinha como opção respondê-lo presencialmente ou virtualmente.

5. Encaminhamento às coordenações: Uma quinta etapa disse respeito à estratégia de contato por e-mail com todas as coordenações de curso de graduação da UFSCar, para a coleta de dados quanto ao conhecimento sobre estudantes que são o público-alvo da Educação Especial matriculados em seus respectivos cursos.

6. Contato com a Proace: Outra fonte de dados considerada foi o contato com a Proace, a partir da realização de dois encontros com os responsáveis indicados para a coleta de dados sobre os estudantes com deficiência ou demais necessidades acompanhadas pelos setores da Próreitoria. Os dados foram registrados em diário de campo.

Para a análise dos dados, as informações censitárias obtidas na etapa 2 permitiram um tratamento quantitativo descritivo e as demais etapas passaram por tratamento de análise de conteúdo. Com todos os dados tratados, foi realizada a triangulação das informações qualitativas, de modo a evidenciar os dados alcançados, com o registro e conferência do banco de informações construído.

A Figura 1 a seguir sintetiza as informações obtidas nas etapas de coleta de dados, seus objetivos e procedimentos. 
Figura 1. Etapas e procedimentos de coleta de dados.

\begin{tabular}{ccc}
\hline Etapas & Objetivos & Procedimentos \\
\hline $\begin{array}{c}\text { Contato com a Pró-reitoria de } \\
\text { graduação }\end{array}$ & $\begin{array}{c}\text { Obter os dados dos alunos público-alvo } \\
\text { da Educação Especial da graduação da } \\
\text { UFSCar. }\end{array}$ & $\begin{array}{c}\text { Encontro presencial com realização de } \\
\text { entrevista }\end{array}$ \\
\hline Acesso aos dados da SIN & $\begin{array}{c}\text { Obter os dados dos alunos público-alvo da } \\
\text { Educação Especial da graduação. }\end{array}$ & $\begin{array}{c}\text { Encontro presencial com a analista } \\
\text { de tecnologia da informação da SIN e } \\
\text { disponibilização de acesso ao sistema }\end{array}$ \\
\hline Contato com os alunos & Criação de e-mail para contato com os \\
alunos. & Via e-mail. \\
\hline Preenchimento do formulário & $\begin{array}{c}\text { Coletar demandas dos alunos identificados } \\
\text { como público-alvo da Educação Especial. }\end{array}$ & $\begin{array}{c}\text { Aplicação presencial ou preenchimento } \\
\text { on line. }\end{array}$ \\
\hline Encaminhamento às & $\begin{array}{c}\text { Coletar informações sobre o conhecimento } \\
\text { dos departamentos de curso sobre os } \\
\text { colunos público-alvo da Educação Especial. }\end{array}$ & Via e-mail. \\
\hline Contato com a Proace & $\begin{array}{c}\text { Coletar informações sobre os alunos nessa } \\
\text { pró-reitoria da instituição. }\end{array}$ & $\begin{array}{c}\text { Encontro presencial com coleta em diário } \\
\text { de campo }\end{array}$ \\
\hline
\end{tabular}

Fonte: As autoras (2016).

\section{Resultados}

Os resultados obtidos serão apresentados conforme as etapas de coleta de modo a contextualizar para o leitor o caminho por dados mais assertivos acerca da identificação do público-alvo da Educação Especial nos cursos de graduação da UFSCar. Uma informação importante sobre o processo de identificação do estudante pela universidade diz respeito à forma de ingresso. A partir de 2009, a UFSCar teve todas as suas vagas ofertadas pelo Sistema de Seleção Unificada (SISU), e com isso, não houve a partir de então a coleta de dados cadastrais dos estudantes feitos pela própria universidade durante o processo seletivo de ingresso. Assim, algumas informações passaram a ser extraídas do cadastro junto ao SISU e as demais, solicitadas para autopreenchimento pelo estudante quando já matriculado e inserido no sistema próprio da universidade.

Os dados provenientes da Prograd revelaram que a universidade ainda não possuía um banco de dados estabelecido na UFSCar que abrangesse e identificasse com clareza os estudantes alvo da Educação Especial. Porém, a etapa 1 também informa que a acuidade desses dados está na agenda de reformulação do sistema, o qual tem passado por um processo de readequação desde 2000, que foi o ano de sua criação. Para suprir as demandas do Censo do Ensino Superior, ações de recadastramento dos alunos em 2014 foram realizadas para a atualização dos dados cadastrais dos estudantes por meio de um formulário de preenchimento obrigatório para todos os estudantes que faziam a rematrícula no segundo semestre de 2014. Assim, o sistema da universidade trabalha sob a autodeclaração do estudante sobre sua condição.

Com os dados da etapa 2, obtidos então pela autodeclaração dos estudantes em seus registros no sistema insti- tucional, é possível observar que na UFSCar abrangendo os campi de São Carlos, Sorocaba, Lagoa do Sino e Araras foi identificado um total de 154 estudantes matriculados na instituição em 2014 que se enquadraram nas categorias existentes. Especificamente quanto às categorias atribuídas, foi observada a presença de 1 estudante com altas habilidades/ superdotação, 104 estudantes com deficiência auditiva, 18 com baixa visão ou visão subnormal, 1 com cegueira, 1 com condutas típicas, 7 estudantes com deficiência física, 1 com deficiência intelectual, e 21 estudantes que possuem outras necessidades não especificadas.

Já no que diz respeito ao ano de 2015, a quantidade de estudantes público-alvo da Educação Especial por meio da autodeclaração era de 97 estudantes. Quanto às áreas atribuídas totalizaram-se: 1 estudante com altas habilidades/ superdotação, 52 estudantes com deficiência auditiva, 18 estudantes com baixa visão ou visão subnormal, 7 com deficiência física, 1 com deficiência intelectual e 18 classificados em outras necessidades.

Na tabela 1 a seguir é possível observar os dados obtidos nesse estudo quanto às categorias informadas e sua frequência entre os anos de 2014 e 2015.

A identificação de um número expressivo de estudantes na categoria de deficientes auditivos direciona a duas hipóteses: que realmente os estudantes com deficiência auditiva eram a maior quantidade dos presentes na universidade ou que a estratégia de coleta de dados pela universidade não estava adequada para realmente agregar informações sobre os estudantes público-alvo da Educação Especial.

De forma a buscar estratégias de validação dos resultados obtidos pela autodeclaração, os dados levantados na etapa 3 com o envio de e-mail a 124 estudantes matriculados na instituição, indicam que houve o retorno de 44 e-mails sendo que 17 responderam imediatamente que 
Tabela 1. Número de estudantes de graduação que se autodeclaram por Categoria em 2014 e 2015.

\begin{tabular}{lccc}
\hline \multicolumn{1}{c}{ Categorias de deficiência } & $\begin{array}{c}\text { Frequência } \\
\left(2^{\circ} \text { sem/ } 2014\right)\end{array}$ & $\begin{array}{c}\text { Frequência } \\
\left(1^{\circ} \text { sem/ 2015) }\right.\end{array}$ & $\begin{array}{c}\text { Frequência } \\
\left(2^{\circ} \text { sem/ 2015 }\right)\end{array}$ \\
\hline Altas Habilidades/superdotação & 1 & 1 & 1 \\
Auditiva & 104 & 65 & 18 \\
Baixa Visão ou Visão subnormal & 18 & 20 & 0 \\
Cegueira & 1 & 1 & 0 \\
Condutas Típicas & 1 & 1 & 7 \\
Física & 7 & 8 & 1 \\
Intelectual & 1 & 1 & 18 \\
Outras Necessidades & 21 & 21 & 97 \\
Total & 154 & 118 & 7 \\
\hline
\end{tabular}

Fonte: As autoras (2016).

não faziam parte do público-alvo. Dessa forma, esses estudantes foram orientados a preencher de forma correta seus dados no sistema; e 27 responderam como tendo alguma das categorias listadas (9 deficiência auditiva; 7 deficiência física; 1 altas habilidades/superdotação; 4 baixa visão ou visão subnormal e 5 outras necessidades). Cabe ressaltar que apenas 124 estudantes identificados na etapa 2 possuíam endereço de e-mail informado e atualizado no sistema.

Com os procedimentos de coleta diretamente com os alunos, houve a implantação da etapa 4 em que foi possível mapear as barreiras enfrentadas por oito dos 27 estudantes identificados a partir do preenchimento do questionário construído para tal. Por meio da análise qualitativa das respostas, quatro categorias de barreiras foram elencadas: 0 constrangimento ao falar sobre a deficiência, a falta de acessibilidade no campus, a falta de compreensão de alguns docentes para adaptação de materiais e a compreensão sobre a situação enfrentada. Sobre essas barreiras, foi possível obter uma caracterização de demandas que esses alunos indicaram trazer à instituição de ensino: materiais adaptados e estratégias diferenciadas de ensino como textos digitalizados, partituras em editor para ampliação, a proposições didáticas diferenciadas (no uso da lousa: explanações mais lentas, escrita com letras maiores e legíveis), melhoria de fones de ouvido para cursos à distância, necessidade de maior disponibilidade e flexibilização dos docentes quanto aos procedimentos de avaliação.

Um dado importante advindo dessa etapa diz respeito à informação de que havia outros estudantes que se enquadravam no público-alvo da Educação Especial matriculados em cursos de graduação da UFSCar; porém, que preferiam não ser reconhecidos. Inclusive, optam por não se autodeclarar no sistema de matrículas da instituição.

Por fim, quanto à busca por informações junto às coordenações de curso e à Proace, os dados da etapa 5 com contato via e-mail com as coordenações do cursos de graduação da UFSCar revelaram o retorno de apenas
4 coordenações de curso (Engenharia de Produção (campi São Carlos), Estatística, Imagem e Som, Engenharia Mecânica retornaram os e-mails que foram enviados, sendo que nenhuma destas coordenações possuía ciência sobre as necessidades de estudantes matriculados em seus cursos, indicando assim um possível distanciamento entre a gestão do curso e os estudantes. Quanto ao contato com a Proace (Pró-reitoria de Assuntos Comunitários e Estudantis) da UFSCar por meio de um setor que congrega o atendimento em Assistência Social aos estudantes da universidade, houve a informação de que os casos do campus São Carlos que chegaram até esse serviço eram apenas dois e que ambos os casos se tratavam de estudantes com deficiência física que solicitavam serviços para casos de alojamento estudantil junto à universidade em locais que fossem acessíveis.

\section{Discussão}

O presente estudo inserido na agenda de investigações do OBEDUC na UFSCar, teve como intenção mapear quem eram os estudantes público-alvo da Educação Especial nos cursos de graduação e, nesse percurso, estabelecer estratégias de busca e conferência dos dados encontrados por meio da autodeclaração, como forma de auxiliar à universidade e o núcleo de acessibilidade em organizar estratégias mais eficientes de identificação desse alunado.

Os resultados permitiram constatar as dificuldades em obter a quantidade e a caracterização reais de estudantes que compõem o público-alvo da Educação Especial inserido na universidade em questão, como já apontado por Zampar (2013). Foi possível observar nos resultados do estudo que a universidade acompanhou as mudanças dos formulários para atender aos requisitos censitários, porém essas novas opções e categorias foram ao longo do ano agregados ao formulário de identificação do estudante sem uma nova ordenação do mesmo, mantendo-se 
ainda categorias ultrapassadas como Condutas Típicas, por exemplo. Assim, devido às falhas do sistema de coleta de dados da universidade, muitos dos estudantes que não possuem orientações adequadas quanto a compor ou não o público-alvo das ações de acessibilidade acabam por fornecer informações errôneas sobre sua identificação, como os casos encontrados quanto à baixa visão ou deficiência visual por estudantes usuários de óculos. Esses apontamentos indicam uma fragilidade em como os dados são colhidos e sistematizados pela universidade.

Identifica-se, portanto, que há a necessidade de certificação dos instrumentos e ações mais adequadas para realmente acessar e mapear os estudantes público-alvo da Educação Especial. Essa preocupação se estabelece no sentido de que se a universidade não permite uma coleta de dados real, já que podem haver subnotificação ou supernotificações.

Nessa direção, após o contato com os estudantes presencialmente, pode-se constatar ainda uma problemática acerca dos estigmas que esses estudantes sofrem no ambiente educacional e que muitos deles preferem se manter no anonimato quanto à sua condição, não solicitando auxílios ao núcleo de acessibilidade ou demais órgãos gestores de referência, inclusive à própria coordenação de seus cursos. Assim, apesar da amostra reduzida de estudantes participantes dessa etapa do estudo, as barreiras identificadas corroboram com a literatura, principalmente na ordem da capacitação dos professores e adequação das estratégias didáticas, o fornecimento de recursos apropriados e garantia da acessibilidade plena (Almeida \& cols., 2015, Cabral, 2017).

As falhas nesse processo de identificação, seja por busca ativa da universidade ou mesmo do estudante em se identificar, traz implicações diretas ao fluxo de atendimento do aluno, acarretando muitas vezes em uma ineficiência do serviço de acompanhamento que deve ser promovido pelos campi na garantia de direito à educação a todos os seus estudantes matriculados.

\section{Considerações finais}

A proposta apresentada é resultado de uma composição entre a universidade e o estudante nesse processo. Assim, considera-se importante que sejam elaborados e aplicados instrumentos mais eficazes contendo as explicações das categorias disponíveis para que os estudantes, realmente, possam assinalar de forma adequada essas informações. E que as estratégias de preenchimento exclusivamente por autodeclaração devem ser suplantadas por outros caminhos tendo em vista sua fragilidade. Inclusive, vale apontar que o processo de audodeclaração no âmbito do ensino superior é discutido quanto à sua complexidade, onde muitas vezes os alunos optam por não serem reconhecidos devido a questões de ordem cultural e envoltos em estigmas ainda presentes nesse espaço educacional (Cabral, 2017). Há questões importantes de preconceito que rodeiam esses estudantes e que precisam ser trabalhadas diariamente no âmbito do ensino superior, para que eles e sintam inclusive mais seguros em expor suas necessidades e buscar seus direitos na garantia da participação plena (Castro \& Almeida, 2014; Guerreiro, Almeida, \& Silva Filho, 2014).

Por fim, considera-se que o estudo foi um passo importante na mobilização da instituição quanto à temática do acesso e permanência dos estudantes público-alvo da Educação Especial na universidade. Apesar de pontual, o seu processo trouxe impactos positivos no diálogo com os setores institucionais e grupos de estudantes, o que indica que há um terreno propício para o diálogo e a implementação de mudanças no provimento de ações para a garantia do direito à educação superior de todos os seus estudantes.

Atualmente, entende-se que com a consolidação da Secretaria Geral de Ações Afirmativas, Diversidade e Equidade (SAADE) em 2016 junto à universidade (Universidade Federal de São Carlos, 2016), as ações concernentes aos estudantes público-alvo da Educação Especial deverão ganhar um espaço institucional de destaque e que o estudo realizado pode contribuir para identificar caminhos fragilizados e para o fornecimento de um banco de informações referente aos estudantes nos anos de 2014 e 2015.

\section{Referências}

Almeida, J.G.A.; Bellosi, T.C.; Ferreira, E.L. (2015). Evolução da matrícula de pessoas com deficiência na educação superior brasileira: subsídios normativos e ações institucionais para acesso e permanência. Revista Iberoamericana de Estudos em Educação, 10 (esp), 643-660.

Brasil. Ministério da Educação. Secretaria de Educação Especial. (2008). Política nacional de educação especial na perspectiva da educação inclusiva. Brasília: MEC, Secretaria de Educação Especial.

Cabral, L.S.A. (2017). Inclusão do público-alvo da Educação Especial no Ensino Superior Brasileiro: histórico, políticas e práticas. Revista de Educação da PUC-Campinas, 22 (3), 371-287.

Castro, S.F.; Almeida, M.A. (2014). Ingresso e permanência de alunos com deficiência em universidades públicas brasileiras. Revista Brasileira de Educação Especial, 20 (2), 179-194.

Ciantelli. A.P.C.; Leite. L.P.; Martins, S.E.S.O. (2015). Inclusão no Ensino Superior: mapeamento e análise da matrícula de alunos com deficiência e/ou mobilidade reduzida na Unesp. In: Mendes, E.G.; Almeida, M.A. (Orgs.) Educação especial inclusiva: legados históricos e perspectivas futuras (pp. 287-302). São Carlos: Marquezine \& Manzini, ABPEE.

Díez, A.M.; Rodríguez, V.H.P. (2015). ¿Educación inclusiva en la Enseñanza Superior?: el caso del alumnado con discapacidad. Revista Iberoamericana de Estudos em Educação, 10 (esp), 599-614.

Fernandes, E.M.; Almeida, L.S. (2007). Estudantes com deficiência na universidade: Questões em torno da sua adaptação e sucesso acadêmico. Revista de Educação Especial e Reabilitação, (14), 7-14. 
Gil, A.C. (1999). Métodos e técnicas de pesquisa social. São Paulo: Atlas.

Gil. A.C. (2008). Metodologia do ensino superior. São Paulo: Atlas.

Guerreiro, E.M.B.R.; Almeida, M.A.; Silva Filho, J.H. (2014). Avaliação da satisfação do aluno com deficiência no ensino superior. Avaliação: Revista da Avaliação da Educação Superior, 19 (1), 31-60.

Guerreiro, E.M.B.R. (2011). Avaliação da Satisfação do aluno com deficiência no ensino superior: estudo de caso da UFSCar. Tese de Doutorado, Universidade Federal de São Carlos, São Carlos, SP.

Lei $n^{\circ}$ 13.146, de 6 de julho de 2015 (2015, 6 de julho). Institui a Lei Brasileira de Inclusão da Pessoa com Deficiência. Estatuto da Pessoa com Deficiência. Brasília.

Lima, D.M.M.P.; Moreira, L.C. (2014). Altas habilidades/superdotação no contexto do Ensino Superior. [Resumo]. In: Associação Brasileira de Pesquisadores de Educação Especial (Org.), VI Congresso Brasileiro de Educação Especial. São Carlos: ABPEE.

Maia, E.N.L.; Rahme, M.M.F.; Diniz, M. (2014). Deficiência e currículo no Ensino Superior: uma análise dos cursos de uma universidade mineira. [Resumo]. In: Associação Brasileira de Pesquisadores de Educação Especial (Org.), VI Congresso Brasileiro de Educação Especial. São Carlos: ABPEE.

Moreira, L.C. (2012). Políticas Inclusivas no Ensino Superior: da Implantação à Concretização. In: Mendes, E.G.; Almeida, M.A. (Orgs.), Dimensões pedagógicas nas práticas de inclusão escolar (pp. 97-106). Marília: ABPEE.

Santana, A.P.O.; Donida, L.O.; Monteiro, A.L.L.C.P.; Silva, S.M. (2015). Acessibilidade e permanência: um estudo do programa institucional de apoio aos estudantes da Universidade Federal de Santa Catarina. Revista Iberoamericana de Estudos em Educação, 10 (esp), 673-689.
Santos, S.D.G.; Fumes, N.L.F. (2012). A inclusão da pessoa com deficiência na educação superior: Um olhar sobre a formação e a prática docente (pp. 109-122). In: Mendes, E.G.; Almeida, M.A. (Org.), Dimensões pedagógicas nas práticas de inclusão escolar (pp. 97-106). Marília: ABPEE.

Serrano, E.A.P. (2015). La educación inclusiva en la Educación Superior: relato del contexto universitario cubano. Revista Iberoamericana de Estudos em Educação, 10 (esp), 583-597.

Torres, J.P.; Calheiros, D.S.; Santos, V. (2016). Inclusão na educação superior brasileira: análise da produção científica. Interfaces da Educação, 17 (19), 296-313.

Unesco. (2009). The UN Decade of Education for Sustainable Development: 2005-2014.

Universidade Federal de São Carlos. (2016). Resolução CoAd nº76, de 12 de junho de 2016. Dispõe sobre a estrutura organizacional da Secretaria Geral de Ações Afirmativas, Diversidade e Equidade. São Carlos: UFSCar.

Zampar, J.A.S. (2013). O estudante com deficiência no ensino superior [Resumo]. In: VII Congresso Brasileiro Multidisciplinar de Educação Especial (pp. 151-155). Londrina.

Zuliani, K.T.; Oliveira, A.P.V.; Kretzmann, M.; Castro, S.F. (2014) Reservas de vagas nos processos seletivos para ingresso de alunos com deficiência em IES. [Resumo]. In Associação Brasileira de Pesquisadores de Educação Especial (Org.), VI Congresso Brasileiro de Educação Especial. São Carlos: ABPEE.

License information: This is an open-access article distributed under the terms of the Creative Commons Attribution License (type CCBY), which permits unrestricted use,distribution and reproduction in any medium, provided the original article is properly cited.

Recebido em: 22/08/2017 Aceito em: 07/11/2017

\section{Sobre as autoras}

Gerusa Ferreira Lourenço (gerusalourenco@gmail.com)

Doutora em Educação Especial pela Universidade Federal de São Carlos. Professora Adjunta nível 3 no Departamento de Terapia Ocupacional da Universidade Federal de São Carlos e no do Programa de Pós Graduação em Educação. São Carlos, São Paulo- SP.

https://orcid.org/0000-0002-7550-4858

Janna Battistella (jannabattistella@hotmail.com)

Graduada em Terapia Ocupacional pela Universidade Federal de São Carlos. Foi bolsista de iniciação científica durante os anos de 2014 e 2017 com o subprojeto de seguinte título: Proposta de construção de um banco de dados sobre alunos com deficiência na Universidade Federal de São Carlos. (Subprojeto do Projeto em Rede Acessibilidade no Ensino Superior CAPES/OBEDUC Edital 49/2012. São Carlos, São Paulo - SP. https://orcid.org/0000-0001-6278-7417 